\title{
Las Ordenanzas de policía urbana de Madrid de 1641
}

\section{The Ordinances of urban police, Madrid 1641}

\author{
Alberto HERRANZ TORRES \\ Profesor de Historia del Derecho \\ Colegio Universitario Cisneros \\ Universidad Complutense de Madrid \\ aherranz@der.ucm.es
}

Recibido: 4 de noviembre de 2013

Aceptado: 23 de diciembre de 2013

\section{RESUMEN}

En el Archivo Histórico Nacional se encuentra un auto del Consejo de 1741, que a su vez tiene inserta una ordenanza de un siglo antes. Dicho documento regula diferentes aspectos de la vida cotidiana madrileña, tales como edificación de casas, ornamentos, solares y el ejercicio de diferentes oficios comerciales. El aumento de la población hace que la salubridad sea un tema preocupante, por tanto, se crearán normas encaminadas a solucionar este problema, incluyendo tanto a los particulares como a los profesionales que por su oficio produjeran residuos nocivos. Se decide privilegiar algunas calles de Madrid eximiéndolas del tráfico rodado y del estacionamiento en las mismas. Por último, establecerán cual será el procedimiento y las penas que se impondrán a los sujetos que infrinjan estas ordenanzas.

PALABRAS CLAVE: Ordenanzas, Madrid, procedimiento, policía urbana, regulación de oficios, casas y ornamentos.

\begin{abstract}
The National Historical Archive preserves an order of the Council of 1741, which in turn has an ordinance inserted from a century before. This document regulates different aspects of the Madrid daily life, such as building houses, ornaments, terrains and the exercise of various commercial trades. The increase in population levels concerns their health, therefore, rules were created, designed to solve this problem. These rules addressed both individuals and professionals about their craft producing hazardous waste. It was decided that some streets of Madrid would be privileged, exempting them from road traffic and parking. Finally, procedures and penalties were established to be imposed on individuals who violated these regulations.
\end{abstract}

KEYWORDS: Ordinances, Madrid, procedure, city police, regulatory offices, houses and ornaments.

\section{RÉSUMÉ}

Dans l'Archive Historique National espagnol s'est conservée une commande du Conseil de 1741, qui à son tour insérte une ordonnance d'un siècle avant. Ce document réglemente divers aspects de la vie quotidienne de Madrid, tels que la construction de maisons, les ornements, les terrains et l'exercice des différents métiers commerciaux. L'augmentation de la population fait de la santé une préoccupation, et, par conséquent, des règles visant à résoudre ce problème ont été créées, y compris pour les particuliers et pour les professionnels qui, par leur métier, produisaient des déchets dangereux. Il a été décidé de 
privilègier quelques rues de Madrid en les exemptant de la circulation routière et du parking sur place. Finalement, on a mis en place des procédures et des sanctions qui devaient être imposées sur les individus qui violent ces règlements.

MOTS CLÉ : ordonnances, Madrid, procédure, police de la ville, réglementation des bureaux, maisons et ornements.

\section{ZUSAMMENFASSUNG}

Im Staatsarchiv befindet sich ein Autograph des Rates (Consejo) von 1741, der wiederum eine Ordonnanz des vorhergehenden Jahrhunderts enthält. Besagtes Dokument regelt verschiedene Aspekte des täglichen Lebens in Madrid, wie zum Beispiel den Hausbau, den Ornat (die dort angebrachten Verzierungen), Grundstücksangelegenheiten und die Ausübung verschiedener kaufmännischer Berufe. Das Bevölkerungswachstum führte dazu, dass die Hygiene ein besorgniserregendes Thema wurde; zur Verbesserung der Situation wurden daher Vorschriften in Kraft gesetzt, die sowohl für Privatpersonen als auch für Berufsträger galten, die berufsbedingt gesundheitsgefährdende Schadstoffe erzeugten. So wurde beschlossen, einige Straßen Madrids zu privilegieren, indem sie vom fließenden Verkehr und vom Parken dort befreit wurden. Schließlich wurde ein Sanktionensystem für all diejenigen geschaffen, die gegen diese Ordonnanzen verstießen.

SCHLÜSSELWÖRTER: Ordonnanz, Madrid, Verfahren, städtische Polizei, Gewerbeordnung, Regelung betreffend Handwerk, Häuser und Verzierungen.

SUMARIO: I. Introducción. II. Reordenamiento de la Corte madrileña. III. Las Ordenanzas Municipales. 1. Establecimiento de los límites de las casas y las obras nuevas en inmuebles y solares. 2. Control de los carruajes. 3. Regulación de los oficios, ejecución de los mismos y venta de las mercancías. 4. Higiene en la Urbe. 5. Regulación del ornamento de la urbe madrileña. 6. Control de paso de piaras. 7. Procedimiento para ejecutar esta ordenanza, penas, registro y derechos. IV. Conclusión.

\section{Introducción}

Para la realización de este trabajo vamos a analizar un documento perteneciente al Archivo Histórico Nacional, sección Consejos, legajo 51.434-11.

Dicho legajo contiene dos documentos, el más moderno es un auto mediante el cual el Consejo, manda que se copie una Ordenanza dada a Madrid en 1641, el segundo documento será la propia ordenanza, que lleva por título sobre el modo de fabricar casa en Madrid y otros puntos del ornato de la Corte.

La importancia de este documento no radica en el contenido de la norma jurídica en sí, que es importante y novedoso, sino en el problema acuciante que se repite durante toda la Edad Moderna: el control de las edificaciones, la regulación de la actividad de los artesanos y la salubridad de la propia Corte; problemas que aparecen con la creación de las primeras ciudades en la Edad Media y que se van repitiendo de un modo cíclico.

Las Ordenanzas que analizamos representan los problemas de la villa de Madrid, nos permiten analizar la sociedad e incluso la urbanización de la Villa, en un proceso de tejer y destejer que se ha continuado hasta nuestros días y continuará. 
Por tanto, nos encontramos con un auto del Consejo de 1767, pero la ordenanza que se copia es de 1641, justamente observamos que 126 años antes tenían los mismos problemas que no se terminaron de solucionar, por una parte, debido a la inactividad de las justicia y por otra la desobediencia de los ciudadanos; debemos analizar estas ordenanzas desde una perspectiva temporal, ya que artículos de esta norma serán recogidos y utilizados por Teodoro Ardemans ${ }^{1}$ en 1754. Entre estas dos ordenanzas se encontraba la obra de Iván de Torrija ${ }^{2}$, de 1661, donde se establecía un tratado sobre las ordenanzas de la villa de Madrid y su control, con articulado tomado de estas ordenanzas que editamos, que, a su vez, será utilizado por Ardemans, copiando preceptos completos para su obra. Pero, naturalmente, si analizamos también los Libros de Acuerdos del Concejo de Madrid, tanto los de finales del siglo XV como los posteriores, encontraremos disposiciones sobre estos temas.

\section{Reordenamiento de la Corte madrileña}

Será a partir del siglo XIV cuando la villa de Madrid empiece a preocuparse por la remodelación de sus infraestructuras, aunque sólo en el siglo XVI se consolidará esta situación.

El Consejo, utilizando su competencia en urbanismo, decide modificar y remodelar la villa de Madrid, en primer lugar, para recuperar el derruido casco amurallado, consolidando su propia posición como Corte madrileña, pero también decide urbanizar los arrabales, para dar cabida al nuevo flujo de ciudadanos que deciden asentarse en la capital.

Como el resto de ciudades modernas que se precien, Madrid necesita una Plaza Mayor que potencie tanto la vida comercial como administrativa, convirtiéndose en

\footnotetext{
${ }^{1}$ Teodoro Ardemans, Ordenanzas de Madrid, y otras diferentes, que se practican en las ciudades de Toledo y Sevilla con algunas advertencias a los Alarifes, y particulares, y otros Capitulo añadidos a la perfecta inteligencia de la materia, que todo se cifra en el Gobierno político de las Fábricas, Madrid, 1754. ${ }^{2}$ Iván de Torrija, Tratado breve, sobre las ordenanzas de la villa de Madrid y policía de ella, Madrid, 1661. Este tratado es utilizado por Ardemans en sus Ordenanzas, el autor tratas de diversos temas: 1. La regulación del Alarife para controlar el cumplimiento de la ordenanza así como su nombramiento. 2. La construcción y mantenimiento de los canales, así como aquellas que estuviesen en una pared medianera. 3. Los sumideros realizados en el terreno, así como de los pozos tanto para particulares como para artesanos. En esta línea estarán recogidos también las norias y estanques, pilones. 4. Fábrica de sótanos, tapias de medianería. 5. Los portales públicos. 6. El ornamento público, cerramientos de la ventanas o medianerías, paredes entre vecinos, palomares, ventanas, gateras, poyos empedrados y postes en las calles públicas, lo vuelos de las rejas y balcones, canalones de madera, minas y encañados de las fuentes, las puertas que se abren a las calles públicas 7. Protección especial de las obras que se realicen frente a Monasterios. 8. Mobiliario de la vía pública, como pilastras, postes en los portales o calles públicas, las lumbreras, los alzados o fachadas que tocan a la policía. 9. Gestión y fabricación de los hornos, chimeneas y cuevas. 10. Gestión de ámbito civil como son la tasación de edificios de dos alturas, partición de una casa por sus herederos, como se darán entradas a las heredades que no las tienes, control sobre las compraventas de inmuebles, huertas, molinos 11. De los Alfares, jabonerías y yeserías.
} 
un núcleo de transacciones comerciales y mentidero de la villa ${ }^{3}$. Será tan importante esta cuestión que, como veremos en estas ordenanzas, se da un trato especial a esta Plaza y calles adyacentes, no sólo regulando y controlando su pulcritud, sino los oficios que se se desempeñaban en la misma, la regulación del tráfico rodado, así como el propio ornato. Todo esto para convertir esta zona en un lugar donde se potencie el comercio, pero también en zona emblemática que refleje la grandeza del Imperio, compitiendo, en este sentido, con las otras grandes capitales europeas.

Para poder llevar a cabo este cambio tan importante se tomarán una serie de medidas en diversas materias y competencias, como serán las licencias para obras públicas, manteniendo el mismo ornamento en diferentes distritos, elaboración de nuevas ordenanzas, edificación de nuevos edificios, derribo de aquellos que estuviesen fuera de las nuevas demarcaciones, garantizar el cumplimiento de las normas, estableciendo a su vez un personal municipal que controlase estos campos de acción; también tendrán que modificarse las competencias de los alarifes, que dependían exclusivamente del Consejo ${ }^{4}$.

Son muchos los cambios que se suceden en la capital madrileña, sobre todo la gran obra acontecida a finales del siglo XV, que será la pavimentación de las principales calles de la villa así como de los arrabales ${ }^{5}$, pero nos vamos a centrar, en este trabajo, en las materias que regula esta ordenanza.

\section{Las Ordenanzas Municipales}

Dentro de la Historia europea occidental uno de los hitos más importantes, que modificará el concepto de la sociedad, será el nacimiento de las ciudades y la formación de la burguesía como tercer estamento. Hasta el momento las clases privilegiadas, y seguirán siéndolo después, eran la nobleza y el clero; a partir de la consolidación de las ciudades completará el organigrama social la burguesía, algunos autores dirán que incluso la complementa ${ }^{6}$. En nuestro sistema castellano será importante la aparición de las ciudades sobre todo por su representación en Cortes, su organización en concejos y el peso que tendrá en la historia la política municipal.

Uno de los problemas principales que encontramos en la grandes urbes es el mantenimiento de la salubridad y de la policía; esto no quiere decir que el las villas con menos densidad de población no tengan los mismos problemas, pero se podían acometer soluciones de forma más rápida y eficaz, ya que el hecho diferencial era el volumen de población. Un atisbo de estos problemas se le plantearán a Madrid ya desde el momento de su reconquista por Alfonso VI ${ }^{7}$.

\footnotetext{
${ }^{3}$ Carmen Losa Contreras, El Concejo de Madrid en el tránsito de la Edad Media a la Edad Moderna, Madrid, 1999, p. 484.

${ }^{4}$ Ibidem, p. 485.

${ }^{5}$ Idem, p. 488.

${ }^{6}$ Henri Pirenne, Las ciudades en la Edad Media, Madrid, 1984, p. 139.

${ }^{7}$ Cristina Segura Graiño, "A modo de introducción a la historia del Madrid Medieval”, El Madrid Me-
} 
Esto aparece ya con la creación de las primeras ciudades, por el aglutinamiento de ciudadanos en un espacio reducido, con sus secuelas de salubridad, control de los buenos usos y costumbre de la ciudadanía, así como la supervisión policial de dicho espacio. La policía sanitaria, en este sentido, es importante para evitar la presencia de enfermedades, epidemias que con tanta facilidad recorrían las ciudades. Uno de los aspectos que más llamaban la atención a los nuevos pobladores de las ciudades era el ambiente terriblemente cargado de las ciudades. Por tanto, desde los orígenes las administraciones locales deberían establecer normas para el buen funcionamiento de la salubridad misma.

El procedimiento que se va a utilizar es la ordenanza: mediante esta norma se regulaban estos aspectos de la policía urbana, siguiendo un sistema que se repite en la mayoría de estas disposiciones; contiene una parte dispositiva, donde se describe una conducta bien prohibida, bien de obligatorio cumplimiento, que por tanto había que observar, terminando con una multa en caso de contravención de la misma. El procedimiento a utilizar es muy sencillo, como en muchas ordenanzas viene recogido. La multa, como dirá el profesor Porras Arboledas ${ }^{8}$, será la consecuencia lógica del incumplimiento de la conducta contemplada en la parte dispositiva de la ordenanza, que los contemporáneos interpretaban como pena pecuniaria; eso sí, sin que faltasen otro tipo de penas.

Por tanto, como norma general, las ordenanzas urbanas recogían de normativa de orden público, la regulación de actividades municipales y abastos, esto es, obligaciones generales y particulares de aquellos sujetos respecto del municipio9.

Según la división realizada por el profesor Porras Arboledas, estaríamos ante ordenanzas de policía urbana, atendiendo, concretamente, a los temas de ornato y construcción, circulación de vehículos, salubridad, desempeño de oficios artesanales y compraventa de mercancías, todo ello completado con las disposiciones procedimentales habituales.

dieval. Sus Tierras y sus Hombres, Madrid, 1990, p. 15. Un asunto problemático es la fecha de la conquista de Madrid por Alfonso VI: unos defienden que se produjo antes de la caída de Toledo, como pase previo a la conquista de la antigua capital visigoda, en 1083, mientras que otra parte de la historiografía defiende que fue posterior a la conquista de Toledo, en 1085, siendo consencuencia de la misma la entrega de los lugares próximos, como Madrid.

${ }^{8}$ Pedro Andrés Porras Arboledas, "Las ordenanzas municipales. Algunas propuestas para su estudio y un ejemplo", Espacio. Tiempo y Forma. Serie III. Historia Medieval, VII, 1994, p. 54, en el presente artículo establece una descripción general de los temas que tratarán las Ordenanzas, como son: abastos, aguas, bienes comunales, concejos, gremios, Mesta, montes, oficios, pastos y ganadería, pósito, bienes de propios, rentas y términos. Aunque utilizaremos la siguiente relación que realiza el autor por materias, para hablar de las Ordenanzas de Madrid: policía rural, policía urbana (incluyendo la política de abastos), la gestión de rentas, propios y comunes y la organización administrativa del municipio.

${ }^{9}$ Pedro Andrés Porras Arboledas, "Fueros, privilegios y ordenanzas de la villa de Jódar. Cinco siglos de derecho municipal”, Historia. Instituciones. Documentos, XXI, 1994, p. 405. 


\section{Establecimiento de los límites de las casas y las obras nuevas en inmuebles y solares}

Un tema central es el establecimiento de las nuevas obras y remodelaciones de las viviendas construidas. La principal problemática es garantizar la seguridad de los vecinos que viven en estos inmuebles, en segundo lugar la importancia de establecer una red de calles óptima y no el laberinto existente de casas unidas, dejando calles de trazado imposible, que dificultaban la movilidad de personas y mercancías.

La preocupación se centra solamente en los límites medianeros, con el aumento de la urbe, sobre todo desde el inicio del siglo $\mathrm{XV}$, donde también se generalizarán las prohibiciones de salientes, voladizos y todos aquellos elementos que puedan perjudicar a los viandantes, poniendo en riesgo tanto la seguridad como el libre tránsito, por sí mismo bastante angosto, al crecer la ciudad sin un plan de urbanismo preestablecido. Este tema se regulará también por pragmática real en 1497, pues será en el reinado de los Reyes Católicos cuando la Corona comience a gestionar la planificación urbanística de las ciudades debido al incremento de éstas.

El concejo madrileño tomó dos vías para la aplicación de esta normativa, una severa y otra más benevolente, sin un criterio claro. En unos casos, aplicó taxativamente la legislación real y las ordenanzas, imponiendo penas elevadas para los infractores, ejecutando expedientes de derribo, denegando licencias tanto para ejecuciones de obra como para incorporar terrenos municipales, aunque sea en detrimento de personajes poderosos ${ }^{10}$. Esta actuación se vio avalada por las sentencias del Consejo Real, dictadas en estos $\operatorname{casos}^{11}$.

Las licencias de obras que se van a ir otorgando, así como su regulación en las ordenanzas, transmiten la preocupación que tiene el concejo de Madrid para intentar homogeneizar la trasformación de viviendas; comparando la ciudad de Madrid con la de Toledo, se ve claramente la preocupación que tenían los distintos concejos de Castilla, para que todas las construcciones tuvieran cierta uniformidad, ya que el abuso de los vecinos era considerable; destacamos entre ellas la prohibición de edificar voladizos, portales invadiendo el suelo, vuelo de las calles públicas, licencias que afectaban a calles privadas o secundarias dentro de la propiedad de un sujeto ${ }^{12}$.

\footnotetext{
${ }^{10}$ Carmen Losa Contreras, El Concejo de Madrid ..., p. 493. La profesora Losa Contreras, pone de ejemplo a los Marqueses de Moya, a los que se les impidió la adquisición de terrenos municipales; en este caso, según la documentación analizada, hay que tener en cuenta también la lucha de bandos y las enemistades que tendrían los marqueses, debido a los privilegios concedidos por los Reyes Católicos en detrimento de la ciudad de Segovia. En este caso estos nobles abogaron por la denegación de terrenos municipales para que su poder no se extendiese y tuviesen un palacio-castillo como el que construyeron en Segovia. Pero simplemente habrá que esperar unos años, cuando los marqueses afiancen su poder y se les otorgue el título de condes de Chinchón para que puedan obtener las licencias necesarias para las nuevas edificaciones y adquisiciones de propiedades.

${ }^{11}$ Carmen Losa Contreras, El Concejo de Madrid..., p. 493.

${ }^{12}$ Ibidem, p. 497.
} 
Así pues, estas ordenanzas le dedican 4 artículos a este tema, expuestos en un primer momento; aunque no sean tan numerosas como las normas que tratan de la higiene de la urbe, sí son muy descriptivas y extensas en su regulación.

En esta primera fase de las ordenanzas ${ }^{13}$ encontramos que una de las mayores preocupaciones del Ayuntamiento es establecer los límites de la villa, no pudiendo aumentarse sin el permiso del Consejo, teniendo un control férreo de las nuevas construcciones de edificios como de tierras de cultivo, pues establecerá la ordenanza ${ }^{14}$ :

... están echas y señalados los límites que esta villa ha de tener para que no se labre fuera de ella, ni estienda más su población, ninguna persona de qualquier estado, calidad y condición, que sea no pueda edificar, labrar...

Pero no sólo fijan el control de los propios límites sino también se prohíbe labrar y edificar tierras que estén fuera de los límites establecidos, tampoco se podrán establecer contratos de compraventa, establecer censos, enajenar las propiedades, ya que todo esto será nulo.

La propia ordenanza recoge la pena impuesta para aquellos que no cumplan esta norma, que será deshacer y derribar, siempre a costa de los dueños, los edificios edificados en que se hayan realizado obras dentro de los mismos, debiendo pagar una multa de $10.000 \mathrm{mrs}$, por cada posesión, sitio o solar que incumpliese la normativa, tanto para edificación como para venta.

... y los edificios que se hicieren se mandarán derrivar y deshacer a costa de los dueños de ellos y demás de lo dicho incurran en pena de diez mill mrs. por cada posesión, sitio o solar que se bendiese o edificase contra la dicha orden...

Sólo estarán permitidas las nuevas obras y edificaciones que hubieran sido solicitadas al Ayuntamiento, presentando la planta y traza, y se les otorgase una licencia, deberían cumplir los requisitos de la ordenanza y no podrían perjudicar ni al ornato ni a la policía.

Todas aquellas personas que obtuvieran licencia para ejecutar las obras de construcción y mejora, también deberían de cumplir con las siguientes exigencias - esta ordenanza va unida a las que analizaremos en el apartado de sanidad e higiene-: no se podrán verter los cascotes o todos aquellos materiales que sobrasen de las obras, salvo que se tuviese una licencia del Consejo, superintendente de la limpieza de la

${ }^{13}$ AHN, Consejos, leg. 51.434-11; la ordenanza que estamos examinando, como explicamos en la introducción, está formada por dos documentos, uno de 1767, que es el auto de mandamiento de la copia de la ordenanza de 1641, y el segundo la propia ordenanza, que aparece transcrita al final del documento, que hemos dividido por artículos para un mejor entendimiento y poder citarla con mayor facilidad.

${ }^{14}$ Ordenanzas, art. 1 . 
villa, si no lo tuvieren tendrían que transportar estos materiales y llevarlos a las afueras de la villa ${ }^{15}$.

... no echen en las plazas ni calles públicas la tierra, cascotes, ni otras immundicias, ni broza que sacaren y sobraren de las dichas obras sin licencia del Señor del Consejo superintendente de la limpieza de esta villa, sino que desde sus casas lo hagan sacar y llevar luego al campo.

La consecuencia del incumplimiento de la retirada de escombros y cascotes, será la multa de 6 ducados, repartido su pago por mitades entre el dueño de la casa y el maestro que esté realizando la obra. Para formalizar la denuncia será suficiente con la declaración de los alguaciles o de los porteros, para quitar estos cascotes, que correrán por la cuenta del que hiciese dicha obra; si se opusiese el dueño podrán sacar y vender aquellos bienes que fuesen necesarios para pagar la multa y las costas de la limpiezas de los escombros que estuviesen en la vía pública.

... alguacil o portero les puedan sacar y bender bienes para pagar lo que montare el sacar los dichos terrenos demás de la dicha pena.

Dentro de esta categoría se regularán aquellas construcciones encaminadas a recoger o vaciar agua. Ninguna persona-hace hincapié la ordenanza- de ninguna calidad — nos da a entender que es una práctica extendida entre las clases más pudientes de la sociedad madrileña- puede tener ningún albañal ${ }^{16}$, ni vaciadero, salvo que fuera con raíz de la tierra, o esté levantada del suelo una tercia y no más alto aunque sea para aguas limpias ni llovedizas ni para ningún otro efecto ${ }^{17}$.

Pero si estuviesen realizadas con fecha anterior a la ordenanza, tendrían que cerrarlos y tapiarlos en el plazo de seis días; el incumplimiento de la misma tendrá una pena de $600 \mathrm{mrs}$. También se incluyen dentro de esta norma las yumbreras ${ }^{18}$ de las cuevas no pudiendo estar descubiertas si no estaban tapadas con rejas, arrimadas a la pared y a nivel, y nunca podrán estar extendidas en las calles salvo que el espacio estuviese determinado para tal fin ${ }^{19}$.

\section{Control de los carruajes}

Otra de las preocupaciones importantes que tenían el Consejo era que la vía pública estuviese libre de obstáculos; según se deduce de la ordenanza, parece ser que

\footnotetext{
${ }^{15}$ Ordenanzas, art. 2.

${ }^{16}$ Según la definición de la RAE: canal o conducto que da salida a las aguas inmundas. Depósito de inmundicias.

${ }^{17}$ Ordenanzas, art. 3.

${ }^{18}$ Según la RAE, lumbrera, apertura o tronera o caño que desde el techo de una habitación o desde la bóveda de una galería, comunica con el exterior y proporciona luz o ventilación.

${ }^{19}$ Ordenanzas, art. 4.
} 
era normal ocupar las plazas y las calles por los carruajes. En esta ordenanza ${ }^{20}$ se regula este problema, nos dirá que ningún artesano de carruajes pueda efectuar su oficio en la vía pública, ni dejarlos estacionados mientras se labren o se alquilen, también quedará prohibido que bloqueen las puertas de sus casas, salvo para enganchar las mulas y caballos, siempre y cuando se vayan a utilizar inmediatamente. Los materiales que se necesiten para el mantenimiento de estos carruajes deberán guardarse en el interior de sus casas y no dejarlos en la vía pública; cuando no se utilicen estos carruajes deben guardarse dentro de sus propiedades, dejando libre de transito la vía pública. La pena por el incumplimiento de estas ordenanzas será $600 \mathrm{mrs}$. por cada vez que incurriesen esta ella.

\section{Regulación de los oficios, ejecución de los mismos y venta de las mercancías}

Una de las mayores preocupaciones que tienen estas ordenanzas es la regulación de los oficios dentro de la urbe, la manufactura de productos y su venta. Le dedica 10 artículos dentro de las ordenanzas, aunque no todos se establecen en un orden sistemático de materias.

Los primeros oficios que regulará ${ }^{11}$ serán todos los carpinteros, silleros y ensambladores, entalladores, herreros y otros qualesquier oficios; en esta primera parte lo que les interesa es que estos oficiales no puedan desarrollar su trabajo fuera de sus tiendas, ya que era práctica habitual ejercerlos en la vía pública, a vista de los ciudadanos, así, no podrán sacar sus bancos, ni herramientas, ni poner toldos en la vía pública. Lo que se pena en este caso es el bloqueo de la vía pública, la pena por contravenir la ordenanza, al igual que las ordenanzas sobre carruajes, será de 600 mrs. por cada vez que se incumpliese.

Pero también se establece una protección especial para determinadas calles, o arterias principales de la villa ${ }^{22}$, en donde se prohibirá el ejercicio fuera de las tiendas, que por tradición allí se sitúan y por su actividad están acostumbrados a exponer sus productos en las puertas de sus tiendas, en las ventanas, y cualquier hueco que la fachada permita, y si tienen postes no pueden no puedan embarazar los portales, calles y plaza con mesas, bancos y asientos, arcas, ni cosas de sus oficios, ni salir a ellas más que una tercia acia el portal y media vara acia la plaza o calle donde estuvieren. Estás calles que se protegen son la calle Mayor, Plaza Mayor, calle Toledo y Atocha. La pena es la misma que en los anteriores artículos 600 mrs. por cada vez que se contraviniere el capítulo.

Están separados estos oficios según su insalubridad: los primeros que aparecen son aquellos que simplemente producen incomodidad entre los viandantes, pero no

\footnotetext{
${ }^{20}$ Ordenanzas, art. 5.

${ }^{21}$ Ordenanzas, art. 6.

22 Ordenanzas, art. 7.
} 
contaminan las calles. El segundo bloque está formado ${ }^{23}$ por artesanos que trabajan la madera, los metales, tanto metal viejo como cobre, y los yesos, éstos tampoco podrán desempeñar su oficio fuera de sus tiendas, salvo en tiempo de Feria y en las plazas y calles establecidas, bajo pena de 600 mrs., pena habitual como estamos observando. Pero hay una excepción, se permitirá vender ropa vieja, en la Plazuela de los Herradores, que está delante de la Pasión, pero no en la Puerta y Plaza de Santo Domingo, y no podrán vender esos productos los regatones; pero deberán tener licencia del corregidor y del escribano del Ayuntamiento para este ejercicio y sólo en los lugares determinados en esta norma.

Los siguientes oficios regulados por su peligrosidad serán ${ }^{24}$ los que vendan carbón, leña, paja larga o corta, en carretas o carros, ya que los almacenes estaban en los arrabales de la villa. Sólo podrán llevarlas directamente en carros a vender en la Plazuela de la Cebada, calle de Alcalá; desde el Monasterio de Nuestra Señora de las Vallecas hasta abajo o en la Plazuela de Santo Domingo, ninguna calle está permitida, prohibiéndose que paren, detengan, ni carros ni cabalgaduras; la pena será de $300 \mathrm{mrs}$. por cada carreta, y 200 mrs. por cada carga.

Los que traigan piedra, cal o yeso tendrán que ir a la calle que hay desde la Puerta acesonaria del Hospital de Antón Martín hasta el Monasterio de Santa Ysavel, aplicándose las mismas penas.

También recoge esta ordenanza a aquellos que se dedican a la venta de productos perecederos ${ }^{25}$, bodegoneros y personas que guisan de comer y vender fruta berde $y$ seca, no podrán vender sus productos en mesas, ni braseros en las plazas y las calles, incluso aunque tuviesen el consentimiento de los dueños de las casas donde arrimaren las tiendas, sino que deben dejar los pasos públicos libres y desembarazados.

Los bodegones sólo podrán expender sus productos en las Plazas de Antón Martín, Santo Domingo y Red de San Luis; como siempre en esta ordenanza se deberá tener licencia del corregidor o escribano público del Ayuntamiento o de la policía encargada del ornato. La pena que se establece será: la perdida de la ganancia obtenida más 600 mrs. y la pérdida de la licencia que se entregará a otra persona; prohibiendo la venta y el alquiler de estos puestos, de esta forma el concejo quiere regular la venta de estos productos y acabar con el menudeo y la venta fraudulenta que existía; la pena era la perdida de la licencia, los cajones, el precio de venta y 10 ducados ${ }^{26}$. Esta norma incluirá también a sastres, calceteros, ropabejeros, zapateros, cerrajeros, y tenderos que vendan pan o cualquier otro mantenimiento.

Hace especial hincapié también en los oficios ${ }^{27}$ de fruteros, hortelanos o gallineros, que se les aplicarán las mismas normas anteriormente expuestas con las mismas

\footnotetext{
${ }^{23}$ Ordenanzas, art. 8.

${ }^{24}$ Ordenanzas, art. 9.

${ }^{25}$ Ordenanzas, art. 10.

${ }^{26}$ Ordenanzas, art. 11.

${ }^{27}$ Ordenanzas, art. 12.
} 
penas, tanto de ejercicio y venta como de bloqueo de calles y portales; y dirá, como norma general, a todos aquellos oficios que saquen un banco para el ejercicio del mismo $^{28}$.

Se decide que la protección de las calles establecidas anteriormente se extienda también a la calle Nueva de la Puerta de Guadalajara, calles que corresponden a la Plaza de los Herradores y Plaza de Santa Cruz ${ }^{29}$.

Y por último, en este bloque, regula la actividad de los esparteros ${ }^{30}$, los cuales, sólo podrán vender en los lugares establecidos para ello y el producto deberá estar desembarazado, no en esteras completas, bajo la misma pena de $600 \mathrm{mrs}$. y ser apremiados por ello.

\section{Higiene en la Urbe}

La salubridad era tema acuciante dentro de la problemática de todas las ciudades, ya que era una de las principales causas de las grandes epidemias, nacidas en las ciudades, pandemias que diezmaban la población.

En las ciudades medievales y modernas uno de los puntos más llamativos, para aquellos que se trasladaban a estas grandes urbes, era el intenso hedor que emanaban, lo que dio lugar regulaciones que intentaban ponerle remedio. Recogemos el testimonio de Lambert Wyts, aristócrata de los Países Bajos, miembro del séquito de Ana de Austria, en 1569, que hace las siguientes declaraciones ${ }^{31}$ :

Tengo a esta villa de Madrid por la más sucia y puerca de todas las de España, visto que no se ven por las calles otros que grandes servidores (como ellos los llaman), que son grandes orinales de mierda, vaciados por las calles, lo cual engendra una gran fetidez inestimable y villana [...]. Después de las diez no es divertido pasearse por la ciudad, tanto que, después de esa hora, oís volar orinales y vaciar la porquería por todas partes.

Este testimonio debemos tomarlo con reservas, teniendo en cuenta la opinión que tenía de la Corte de los Austrias; pero sí era un problema acuciante que tratan todas las ordenanzas: la que estamos examinando dedica dos artículos, los más extensos del texto analizado, para solventar este problema.

El Regimiento, con competencia en materia de higiene, establecerá diversas normas para regular este acuciante problema: concretamente destacar que en 1562 se establecieron unas ordenanzas que deberían pregonarse por todas las calles de la Corte

\footnotetext{
${ }^{28}$ Ordenanzas, art. 19.

${ }^{29}$ Ordenanzas, art. 20.

${ }^{30}$ Ordenanzas, art. 21.

${ }^{31}$ David Ringrose, "Madrid, Capital Imperial (1561-1833)", Madrid historia de una Capital, Madrid, 2005, p. 209.
} 
para su cumplimiento. Como no era factible el control higiénico, se distribuyeron las calles en ocho cuarteles, en 1571, ratificando este acuerdo de 1565, pero tampoco surte el efecto deseando, llegará incluso, según las noticias de la época, a que los grandes señores de Madrid, levantasen tapias a lo largo de sus posesiones inmobiliarias para evitar las inmundicias y basuras vertidas en sus puertas.

Debido a esta iniciativa particular en 1571, como nos hemos referido antes, se creará la figura de un encargado, aunque se utiliza la palabra obligado del mantenimiento de la limpieza en la capital, con un coste de $1.000 .000 \mathrm{mrs}$. al año. Tampoco dio un resultado aceptado por todos, porque sólo en las calles más comprometidas de la Corte se mantuvo una limpieza pero no en las inmediaciones de ellas ${ }^{32}$.

El motivo de la poca efectividad será debido a la poca cooperación de la ciudadanía, incluso se llegaron a crear 4 cuadrillas para la limpieza de las calles de la capital, en 1580, aumentando el control por parte de los alguaciles del incumplimiento de esta normativa, incentivos en los salarios, pero no se consiguió paliar el problema; en 1584 recogemos unas declaraciones para explicar la situación ${ }^{33}$ :

... si de mañana se atreve uno a cruzar las calles [...] no es precisamente olor a incienso lo que le llega a uno, sino inmundicias y desechos domésticos que provoca el vómito, como si en ayunas se metiera uno de una pocilga.

Felipe II creará la Junta de Policía ${ }^{34}$ en 1590, que en materia de limpieza no fue tan efectiva como en control de la ciudad, pero sirvió de germen para establecer un control más férreo.

En este contexto histórico aparece nuestra Ordenanza, que nos plantea el problema que se daba en 1641 y en 1767. Será el Concejo quien tenga competencias y atribuciones para velar por la salud e higiene de la villa: obviamente en esta época las ciudades distaban mucho de tener un sistema de tratamiento de residuos como el establecido en la actualidad, pero, según examinamos las actas del Ayuntamiento, vemos que se preocupó mucho el municipio en evitar epidemias ${ }^{35}$ e infecciones; también le correspondía la gestión de cuidados médicos contratando físicos para este servicio ${ }^{36}$.

Una de las medidas básicas que utiliza el Concejo es establecer un sistema de alcantarillado público, cuidando dos aspectos fundamentales, primero apartar del centro

\footnotetext{
${ }^{32}$ Ana Guerrero Mayllo, El Gobierno Municipal de Madrid, Madrid, 1993, p. 192.

${ }^{33}$ Ibidem, p. 193.

${ }^{34}$ Idem, p. 194.

${ }^{35}$ Alfredo Alvar Ezquerra, "La población española: siglos XVI al XVIII", La sociedad española en la Edad Moderna, Madrid, 2005, pp. 39-43. El autor recoge en su obra los distintos tipos de epidemias que diezmaron la población y que traban de frenar todas las ciudades con estas medidas, principalmente la peste, que asolaron Castilla durante los siglos XVI y XVII, destacan las de 1507, 1596-1602, 1647, 1652, 1676 y 1685, siendo las más virulentas las de 1506 y 1647. También se trata de evitar el tifus, la viruela, el paludismo o la malaria, entre otras.

${ }^{36}$ Carmen Losa Contreras, El Concejo de Madrid..., p. 504.
} 
neurálgico de la villa los oficios insalubres, como carnicerías, mataderos y, segundo, las tenerías y la artesanía del cuero, que se serán trasladadas fundamentalmente al barranco de la Hontanilla, evitando así la contaminación del agua que consumían los habitantes y los animales de la villa; esta norma se dará el 14 de julio de $1495^{37}$.

Hemos de hacer un breve inciso en este punto, podemos diferenciar dos enclaves diferenciados dentro de la misma ciudad, que no tienen el mismo cuidado, uno principal serían las calles y arterias principales de la ciudad, fijadas por Felipe IV, estableciendo Madrid-Corte. Pero hay una segunda menos cuidada, donde aparecen las casas bajas, de construcción mediocre, de uno o dos pisos, habitados por muchas familias que tenían una renta mísera, siendo miserablemente pobre incluso para los criterios del siglo XVII. Este entramado estrecho, sucio, sin empedrado, en el cual la vía pública hacía las veces de cloaca, con escasas fuentes de agua limpia, un abastecimiento limitado, siendo foco de todo tipo de infecciones, formaba parte también de este Madrid, situado en los barrios marginales y arrabales ${ }^{38}$.

Un ejemplo que podemos observar es la modificación del matadero de Madrid, porque estaba demasiado cerca del Hospital, corriendo a cargo de Beatriz Galindo el traslado del mismo ${ }^{39}$ :

... sommos informados que un matadero que esta cerca del hospital que en esta villa nueva mente fizieron el secretario Francisco de Madrid, ya defunto, e Beatriz Galindo, nuestra criada, faze muchos malos olores en el dicho hospital e a los que están, e que el agua que está en la cava de la dicha villa podría hazer doliente el dicho hospital, por ende nos vos mandamos que luego busqueys otro lugar conveniente donde el dicho matadero se pueda mudar a costa de la dicha Beatriz Galindo. E otrosy le dexeys e consintays alinpiar dicha cava de manera que no pueda recogerse en ella agua alguna.

Los encargados del cumplimiento de todas las normas son los alarifes, que deben vigilar la limpieza de la vía pública, la higiene en las carnicerías, corrales donde hubiese ganado, atender a las denuncias de obras ruinosas, y señalar los lugares que se convertirán en vertederos y estercoleros, funciones en que estaban subordinados al regimiento ${ }^{40}$.

Para intentar paliar los problemas descritos anteriormente el concejo regula el flujo de aguas residuales ${ }^{41}$ : no se podrá vaciar ningún género de agua sucia, ni limpia

\footnotetext{
${ }^{37}$ Ibidem, p. 507.

${ }^{38}$ David Ringrose, "Madrid, Capital Imperial (1561-1833)", Madrid historia de una Capital, Madrid, 2005, p. 223.

${ }^{39}$ Timoteo Domingo Palacios, Documentos del Archivo General de la Villa de Madrid, Madrid, 1909, tomo IV. Cédula de los Reyes Católicos ordenando al Concejo de Madrid que retirase el Matadero que se hallaba junto al Hospital de Beatriz Galindo, y permitiera a esta señora limpiar a su costa la Cava de la Villa (1501).

${ }^{40}$ Rafael Gibert y Sánchez de la Vega, El Concejo de Madrid. I. Su organización en los siglos XII a XV, Madrid, 1949, p. 246.

${ }^{41}$ Ordenanzas, art. 13.
} 
por las ventanas, azoteas, por criados, ni de día ni de noche. Regula cómo se podrán echar estas aguas en las distintas épocas del año, si es verano, desde abril hasta septiembre, será después de las 11 de la noche, y siempre por las puertas principales y falsas y en la mitad de la calle; si es invierno, desde octubre hasta marzo, podrán echarse estas inmundicias a partir de las 10 de la noche. Los dueños de las casas deberán velar por el cumplimiento de esta normativa, porque la pena se les impondrá a ellos, aunque el delito lo hayan realizado los criados, pena que será de $600 \mathrm{mrs}$., permitiendo que si ha sido por dolo del criado el dueño se resarza de la multa con cargo a su salario.

Para la limpieza de caballerizas, podrán tener carros en la puesta de sus casas o bestias para recoger estiércol.

Al ser una práctica habitual se nombran doce porteros de policía para denunciar a todos aquellos que contraviniesen esta ordenanza, y las causas irán directamente al corregidor y no como hasta el momento a la Sala de Alcaldes o cualquier otro juez, reservando la apelación antes el Consejo y Sala de Gobierno y ante el escribano mayor del Ayuntamiento y no ante otro.

$\mathrm{Si}$ es un tratante de pescado o confitero quien echase las aguas utilizadas en su trabajo - pues deberían deshacerse de ellas fuera de los límites de la villa—, tendrían una pena de 10 ducados y 4 días de cárcel, como vemos la pena más elevada que impone la ordenanza ${ }^{42}$.

\section{Regulación del ornamento de la urbe madrileña}

Para intentar mantener un ornato y una homogeneidad en los edificios de la urbe y debido a las modificaciones que se habían ido realizando sin permiso ni licencia, se prohíbe tener cerrados los balcones, tanto con tabiques, como con tablas, ni realizar cerramientos que ocupen la vía pública; la pena será grave, con 4 ducados y el derribo de las obras prohibidas a costa del dueño de la propiedad; hay un periodo de 4 días para aquellos que lo tuviesen con anterioridad a la norma, para que se deshagan de ello o incurrirán en la pena establecida ${ }^{43}$.

\section{Control de paso de piaras}

Ya en el acta de 23 de julio de 1483 se intenta controlar, mediante una ordenanza, el trasiego de puercos, debido a la suciedad y malos olores que traían, con una pena de 5 mrs. para los dueños de los cerdos que estuviesen sólo en la villa y sus arrabales, aunque en años posteriores se seguirá regulando el mismo tema, con lo cual en principio esta norma no surtió el efecto deseado. ${ }^{44}$.

\footnotetext{
42 Ordenanzas, art. 16.

${ }^{43}$ Ordenanzas, art. 17.

${ }^{44}$ Carmen Losa Contreras, El Concejo de Madrid..., pp. 506 y 507.
} 
También el concejo intervino señaladamente en la zona al ordenar construir un matadero, cuyo objeto era mejorar las condiciones sanitarias de la ciudad concentrando el sacrificio de todas las reses fuera de los muros de la villa. La adopción de medidas higiénicas como ésta demuestra el nivel de desarrollo alcanzado por el concejo madrileño en los últimos años del Medievo ${ }^{45}$.

Sera la ordenanza que estamos estudiando la que intente paliar el problema que en los años anteriores no fue posible: quedará prohibido que los puercos anden por las calles, deberán estar encerrados dentro de las propiedades de sus dueños, se dará un plazo de 2 días para su cumplimiento, si no se cumpliese, se podrá matar al cerdo que se encontrase, sin pena alguna, más pena de $600 \mathrm{mrs}^{46}$.

\section{Procedimiento para ejecutar esta ordenanza, penas, registro y derechos}

El propio texto establece el procedimiento para la denuncia del mismo, así como los testigos que se necesitan; esta es la norma general, porque hemos visto que en anteriores artículos establecía un sistema procedimental propio. Las Ordenanzas le dedican, por tanto, un artículo, y nos dice que simplemente para sentenciar estas causa servirá con la denuncia jurada el portero y la fe del escribano para probar que al denunciado cometió el hecho delictivo ${ }^{47}$.

El reparto de penas se realizará de la siguiente manera, si es materia de ornato se repartirá en terceras partes, una para el corregidor, otra para el denunciador y la última parte para la ayuda de los gastos de limpieza de la Corte $^{48}$.

Deberá registrarse en un libro de condenaciones todas aquellas penas aplicadas, así como el reparto de las mismas, constatando el denunciado, causa, condena y cantidad, este libro lo deberá tener el escribano del Ayuntamiento. También deberá recoger el pago del juez, del portero, del corregidor y las costas de la limpieza que acarrease $^{49}$.

Los derechos que les corresponden al alguacil, al portero y al escribano del Ayuntamiento no podrá ser más de un real y medio; este es uno de los medios de financiación que tenían estos oficiales ya que no recibían sueldo fijo por su oficio ${ }^{50}$.

\section{Conclusión}

Como hemos ido viendo en estas ordenanzas, el concejo de Madrid intenta paliar el ejercicio de los oficios, la salubridad, el libre acceso por las calles y plazas. Pro-

\footnotetext{
${ }^{45}$ Cristina Segura, "Madrid en la Edad Media. Génesis de una capital (873?-1561)", Madrid historia de una Capital, Madrid, 2005, p. 69.

${ }^{46}$ Ordenanzas, art. 18.

${ }^{47}$ Ordenanzas, art. 14.

${ }^{48}$ Ordenanzas, art. 22.

49 Ordenanzas, art. 23.

${ }^{50}$ Ordenanzas, art. 15.
} 
blema que tienen todas las ciudades castellanas, desde sus orígenes y que seguirá incluso en la actualidad.

Estas ordenanzas, que se centran exclusivamente en establecer una convivencia ordenada dentro de la ciudad, serán recuperadas en 1767, fecha del auto de este documento, sin modificar ninguna norma, significando que dicha ordenanza regulaba las necesidades reales de la villa, otra cosa, es, como se puede observar, la inoperancia de la misma o inaplicación, como ha ido sucediendo con las diversas ordenanzas dadas a lo largo de los siglos. Durante la cercanía en el tiempo de la creación de las ordenanzas su aplicación es más que aceptable, pero con el paso de los años se produce un relajamiento excesivo de la misma.

Esta ordenanza servirá de base, en materia de ornamentación, salubridad, desagües y ejercicio de los oficios, para dos posteriores ordenanzas, citadas en el trabajo, las de Iván Torrija y desarrollada años después por Teodoro Ardemans, en su más que famosas ordenanzas de ornato, con una aplicación mayor que la propia villa, ya que se aplicarán también en las ciudades de Toledo y Sevilla. 


\section{APENDICE}

\section{1/08/13. Madrid}

Auto del Consejo de 13 de agosto sobre el modo de fabricar casas en Madrid y otros puntos del ornato de la Corte

En la villa de Madrid, a trece días del mes de Agosto de mill y seiscientos quarenta y un años, los señores del Consejo Supremo de S.M. de la Sala del Gobierno, haviendo visto la desorden que hai en esta villa, sobre lo tocante al ornato y pulicía de ella puniendo en ello el remedio que combiene, mandaron que de aquí adelante se guarde y cumpla lo siguiente:

[1] Que por quanto están echas y señalados los límites que esta villa ha de tener para que no se labre fuera de ella, ni estienda más su población, ninguna persona de qualquier estado, calidad y condición, que sea no pueda edificar, labrar ni dar a censo para edificar ni labrar ningunas tierras, ni solares, que estuvieren fuera de los dichos límites aunque sean juntas a las casas y población pena que las dichas ventas, censos y enagenaciones serán y desde luego se dan por ninguna, y de ningún valor ni efecto y los edificios que se hicieren se mandarán derrivar y deshacer a costa de los dueños de ellos y demás de lo dicho incurran en pena de diez mill mrs. por cada posesión, sitio o solar que se bendiese o edificase contra la dicha orden y sola dicha pena no labren ni edifiquen de nuevo dentro de la población de esta villa ninguna casa ni solar sin pedir o tener licencia del Ayuntamiento de ella y presentar la Planta y traza para que se les dé la ordenanza que han de guardar, sin que se perjudique al ornatto y pulicia.

[2] Que todas las personas que labraren, redificaren o hicieren qualquier obra en qualquier casa de esta villa, no echen en las plazas ni calles públicas la tierra, cascotes, ni otras immundicias, ni broza que sacaren y sobraren de las dichas obras sin licencia del Señor del Consejo superintendente de la limpieza de esta villa, sino que desde sus casas lo hagan sacar y llevar luego al campo, pena de seis ducados, la mitad al dueño de la Casa y la otra mitad al Maestro que hiciese la dicha obra y reparo que a su costa los alguaciles que hicieren la denunciación, los hagan quitar y buscar y concertar quien los lleve citando al dueño de la obra para el dicho concierto, al qual para el mismo perjuicio que si él lo hiciera y precediendo la dicha citación del alguacil o portero les puedan sacar y bender bienes para pagar lo que montare el sacar los dichos terrenos demás de la dicha pena.

[3] Que ninguna persona de qualquier calidad que sea, no pueda usar, ni use ni tenga en su casa ningún albañal ni baciadero sino fuere con raíz de la tierra o por lo menos una tercia levantado del suelo y no más alto aunque sea para aguas limpias ni llovedizas, ni para ningún otro efecto.

[4] Y los que los tuvieren echos contra el thenor de este capítulo, los cierren y quiten dentro de seis días primeros pena de seiscientos mrs. y sola dicha pena no puedan tener las yumbreras de las cuebas descubiertas sino es que las tengan con sus rexas y arrimadas a las paredes y a plomo y nivel, sin que estén tendidas en las calles salvo el que la tubiere en sitio suyo propio.

[5] Que ningún maestro de hacer coches ni carros, ni las personas que tienen por trato y grangería alquilarlos, de aquí adelante no tengan ni labren los dichos coches y carros ni la madera con que los hacen en ninguna plaza ni calle pública de esta villa, ni los alquileres no pongan ni tengan los dichos coches ni carros en las dichas plazas y calles, ni a las puertas de sus casas sino fuese durante el tiempo que pusieren las mulas y cavallos para ir camino con ellos. Y la madera que labraren y tubieren los dichos coches y carros los tengan dentro de sus 
casas, de manera que por ninguna vía, no ocupen las dichas calles ni plazas, pena de seiscientos mrs. por cada vez que contravinieren a lo contenido en este capítulo.

[6] Que todos los carpinteros, silleros y ensambladores, entalladores, herreros y otros qualesquier oficios no tengan ni saquen a la calle sus oficiales ni cosas de sus oficios, ni materiales, bancos y herramientas de sus oficios, encerados, ni toldos ni otra ninguna cosa que ocupen las calles y plazas y vista de las ventanas, ni salgan a travajar a ellas fuera de sus tiendas sino que lo recojan en ellas pena de seiscientos mrs. por cada vez que contrabinieren al contenido en este capítulo.

[7] Que todos los oficiales de los oficios que travajan y tienen sus tiendas y oficios en los postes y portales de la calle Mayor de esta villa, Plaza Mayor, calle de Toledo y Atocha, no puedan salir de sus tiendas a travajar en los dichos portales ninguna mesa ni banco ni otra cosa con que los ocupen ni embaracen el paso, ni en el hueco de ellos cuelguen ningunas cosas de sus oficio ni mercaderías, sino dentro de sus tiendas y los que las tengan en los postes no puedan embarazar los portales, calles y plaza con mesas, bancos y asientos, arcas, ni cosas de sus oficios, ni salir a ellas más que una tercia acia el portal y media vara acia la plaza o calle donde estuvieren pena de seiscientos mrs. cada uno cada vez que contraviniere a lo contenido en este capítulo.

[8] Que todos los que hicieren o vendieren o sacaren a bender qualesquier obras de madera, yeso, cobre u acero u otro qualquier tanero de madera o metal biejo o nuevo o hicieren almonedas o vendieran bienes por oficios de corredores y tengan lo hagan y bendan en sus casas y tiendas sin salir con ellos a las calles y plazas públicas sino fuere en tiempo de Feria pena de seiscientos mrs. por cada vez que hiciesen lo contrario, y se permitiese que puedan hacer almonedas y bender ropa bieja que cada uno tuviese en la Plazuela de los Herradores y en la que está delante de la Pasión ni en la Puerta y Plata de Santo Domingo, bendiendo las mismas personas cuia fuere la ropa o sus criados sin que lo puedan bender regatones y haya de tener licencia del correxidor de esta villa y escribano maior del Ayuntamiento de ella a quien tocase y no se pueda bender en otra ninguna plaza ni calle ni den licencia para ello.

[8] Que todos los vecinos de esta villa o forasteros que vendieren carbón o leña o paja larga o corta en cargar carretas o carros los traigan derechamente a vender a la Plazuela de la Cevada o calle de Alcalá desde el Monasterio de Nuestra Señora de las Vallecas avajo o en la Plazuela de Santo Domingo y no en otra ninguna calle, ni plaza, ni se paren ni detengan en ella ningún chirrionero, ni cabalgadura de carga que se alquilan, pena de trecientos mrs. de cada carreta, carro de chirrión y doscientos mrs. por cada carga y so la misma pena de todos los que sacaren o trujeren a vender piedra, cal o yeso lo vendan en la calle que hai desde la Puerta Acesonaria del Hospital de Antón Martín hasta el Monasterio de Santa Ysavel y no en otra Plaza ni calle.

[9] Que todos los bodegoneros y personas que guisan de comer y vender fruta berde y seca así hombres como mujeres no guisen ni tengan braseros, tiendas ni mesas de los otros mantenimientos en las plazas ni calles públicas aunque sea con consentimiento de los dueños de las casas donde arrimaren o tubieren tiendas sino que dejen las calles y pasos públicos libre y desembarazados. Y que los bodegones los pongan y tengan en las plazas que están señaladas que son las de Antón Martín, Santo Domingo y Red de San Luis y para estas partes han de tener licencias del señor correxidor que es o fuere de esta villa y escribano mayor del Ayuntamiento de ella a quien tocase la pulicía y ornato pena de tener perdidos los mantenimientos que vendieren y seiscientos mrs. Y so la dicha pena guarden y cumplan lo mismo todos los demás que en las 
dichas calles públicas tienen tiendas de sastres, calceteros, ropabejeros, zapateros, cerrageros, $\mathrm{y}$ otros oficios semejantes y tenderos que venden pan y otros qualesquier mantenimientos.

[10] Que los que salen cajones en la Plaza Mayor de esta villa y en la de Antón Martín, Puerta del Sol, Red de San Luis, y Plazuela de Santo Domingo los ayan de tener y tengan con licencia. Y haviéndoles dado los sitios de ellos el correxidor que ha sido, es o fuese de esta villa cuios son los dichos sitios y teniéndola los ayan de tener y tengan proveídos y vendan en ellos sus mantenimientos sin poder vender fuera de los dichos cajones ni salir con los bastimientos más de vara y media desde la tabla y cajón de ellos ni ocupar las dichas plazas con garabixas ni encerados pena de seiscientos mrs. cada vez que contravinieren a lo aquí contenido. Demás de que sino los tubieren proveídos se las quiten y den a otros. Y que no puedan bender los sitios de los dichos cajones, ni alquilarlos pena de tenerlos perdidos y con precio en que lo vendieren y alquilasen y diez ducados so la qual dicha pena, no los puedan dar ni traspasar a ninguna persona sin licencia del correxidor que es o fuese de esta villa y lo mismo se entienda en quanto a las mesas y bancos de las verduleras y garavistos de gallineros.

[11] Que ningún frutero, hortelano ni gallinero salga ni se quite de su puesto, ni con mozos, ni muchachos, ni en otra manera bendan fuera de ellos hortaliza, frutas, berduras, huebos, gallinas ni conejos ni a las puertas de las carnicerías y dejen libre y desocupados los pasos pena de seiscientos mrs. cada vez que lo contrario hicieren.

[12] Que ninguna persona de qualquier calidad que sean no consientan, ni den lugar a que ningún criado ni criadas de día ni de noche, no echen a ninguna hora, ni bacíen ningún género de ymmundicia ni agua sucia, ni limpia por las ventanas ni azoteas de sus casas, sino que lo hechen y bacíen por las puertas principales o falsas de ella en la mitad de la calle y no en otra ninguna parte y las ynmundicias no se puedan echar, ni se hechen sino fuere en Berano, desde primero de abril hasta fin de septiembre después de las once de la noche, en el ynbierno desde primero de octubre hasta fin de marzo después de las diez so pena de seiscientos mrs.; y los dueños de las casas y moradores de ellas avisen a sus criados y criadas que de aquí adelante lo guarden y cumplan porque las dichas penas se han de cobrar de los amos y se les reserva su derecho a salvo para que del salario de sus criados y criadas las puedan cobrar y so la dicha pena, se manda que ninguna persona sea osada de echar en las calles de esta villa ningún género de estiércol de cavallería ni otra cosa. Y quando quisieren limpiar las dichas casas y cavallerizas tengan a las puertas de ellas carros o chirriones o bestias con serones con que lo quiten y saquen en las quales dichas penas, desde luego les dan por condenados lo contrario haciendo aplicadas por tercias partes juez denunciador y obras públicas que para execución de todo lo contenido en este auto y pregón de pulicia y ornato, el correxidor de esta villa pueda nombrar y nombre doce porteros de pulicia y no más los quales hayan de poder denunciar de todos los que contrabinieren a este auto y no otros ningunos, y las causas hayan de pasar y pasen ante el dicho correxidor privativamente con ynivición de la Sala de los Alcaldes y de otros qualesquier jueces y justicias reservándose como se de reserva las apelación de lo que el dicho correxidor hiciere y sentenciare al Consejo y Sala de Gobierno y ante el escribano maior del Ayuntamiento de esta villa a quien toca la dicha pulicía y no ante otro ninguno.

[13] Que para sentenciar las causas que se hicieren, baste sólo la denunciación del portero, jurada y fee del escribano de cómo la persona a quien se denuncia contrabiniendo a lo contenido en este auto y que la notificó a la parte denunciada como siempre se ha hecho.

[14] Que no pueda llevar ni lleve derechos de cada causa más de real y medio para el escribano del Ayuntamiento y el que anduviere con el alguacil. 
[15] Que ninguna persona pueda tener cerrados los balcones de sus casas con tabiques ni tablas ni otra forma, ni salir a la calle con cerramientos, ni enmaderamientos, sino que estén descubiertos todos pena de quatro ducados y que a su costa se quiten los cerramientos que hicieren y los que tuvieren echos dentro de quatro días los quiten y descubran u so la dicha pena.

[16] Que ningún tratante de pescado ni confitero pueda echar a la calle el agua con que remojan el pescado ni la que resulta de tener las frutas los confiteros que una y otra es de mui mal olor sino que en cubas y cubetas lo saquen al campo fuera de esta villa pena por cada vez que la echaren en la calle de diez ducados y quatro días de cárcel.

[17] Que no anden puercos por las calles y los dueños de ellos los recojan y encierren, que no salgan a ellas y si pasado segundo día de cómo se diese este pregón no lo hubieren cumplido qualquiera persona los pueda desaretar y aprovecharse de ellos sin pena ninguna y los dueños yncurran cada vez demás de perdido el ganado, como dicho es, en seiscientos mrs. y el correxidor de esta villa tenga cuidado de hacerlo executar.

[18] Que no puedan ocupar con ninguna mesa, banco, ni oficio, ni estar travajando a las entradas de los portales por la entradas de las bocacalles de ellos sino que los dejen libre y desembarazados para el paso de la jente pena a qualquiera que lo contraviniese de seiscientos mrs. y que se les quite y desembarace las bocas de los dichos portales apremiándolos a ellos por todo rigor de derecho.

[19] Que lo mismo que va proveído a los que tienen tiendas en los portales de la Plaza Calle Mayor, calle de Toledo y Atocha se entienda con los que tienen en los portales de la Calle Nueva de la Puerta de Guadalajara, calles correspondientes a la Plaza Plazuela de los Herradores y Plaza de Santa Cruz so la pena contenida en la condición que de ello trata.

[20] Y que los esparteros no puedan sacar a los portales, calles, plazuelas el esparto, esteras ni otra cosa de su oficio ni ocupar el paso sino que todo esté desembarazado pena de seiscientos mrs. cada vez que lo contravinieren y de ser apremiados a ello.

[21] Que todas las condenaciones que se hicieren sobre lo tocante a la pulicía y ornato se apliquen por tercias partes, la una para el dicho correxidor como juez y la otra para el denunciador, y la otra tercia parte para la ayuda de los gastos de la limpieza de esta Corte.

[22] Y para que en todo haya la quenta y razón que combenga para dar a cada uno la parte que le tocase y tomar la quenta a los porteros, se haya de tener y tenga por el dicho escribano de Ayuntamiento un libro donde se sienten todas las condenaciones por pequeñas que sean, declarando a quién se condenó y en quanto y porque causa y baya tomando la quenta a los dichos porteros y haciendo pago a los dichos porteros y haciendo pago el Juez y Portero, de sus partes y lo demás lo pague a quien el dicho correxidor lo librare y mandare pagar siendo para lo tocante a la dicha limpieza sin que se combierta en otra cosa.

Y para que lo contenido en este auto se guarde y cumpla y benga a noticia de todos y ninguno pretenda ygnorancia se pregone públicamente por pregonero y ante el escribano que de ello de fee en las plazas y calles públicas de esta Villa y Corte.

Y ansí lo mandaron y señalaron. Está rubricado de su señoría Illma. el señor Obispo Governador del Concejo y de los señores don Pedro Marmolejo y don Pedro Pacheco, en Sala de Gobierno.

Concuerda con el original en Madrid dos de octubre de mill y seiscientos y quarenta y un años. Manuel Robles. 
Es copia del auto de los señores del Concejo proveído en trece de agosto de mill seiscientos quarenta y uno, que por certificación se halla en el Libro de Govierno de la Sala del siguiente año de mill seiscientos quarenta y dos, al folio quinientos sesenta y tres y siguientes, hasta. quinientos sesenta y siete a que me remito.

Y de orden de los dichos señores de la Sala, dada a consequencia de lo acordado por los señores del Consejo comunicado por medio de papel el escrivano de Govierno don Ygnacio de Ygareda, su fecha, treinta y uno de marzo próximo.

Yo don Roque de Galdames, escrivano de Cámara del Rey nuestro señor y de Govierno en la referida Sala de los Señores Alcaldes de esta Corte. Doy la presente en Madrid a quatro días del mes de abril de mill setecientos sesenta y siete. Roque Galdames.

Es copia de la certificación original que se remitió a Madrid de que certifico. Madrid ocho de Abril de mil setecientos setenta y siete. Ygnacio de Ygareda.

[Folio posterior] Auto acordado del Consejo de 3 de agostos de 1641, sobre el modo de fabricar casas en Madrid y otros puntos dirijidos al ornato de la Corte mandado guardar en otro posterior de 17 [tachado 13] de marzo de 1767.

Remítase copia certificada a Madrid en 7 de abril con motivo de una instancia que hizo Fr. D. Josehp Hortiz de Zárate, de que ay autos.

Conforme a lo acordado por el Consejo, que con fecha de 31 de marzo próximo me comunicó v.m., se ha sacado la copia certificada del Auto que provehió el Consejo en 13 de agosto de 1641. Y es la que adjunta paso a manos de v.m. para que lo haga presentar al Consejo y sirba a los fines para que la nez[esita].

Dios guarde a v.m. muchos años, como desea. Madrid y abril 6 de 1767. Roque Galdames. Sr. D. Ygnacio de Ygareda. 